\title{
POWER QUALITY AND RELIABILITY SUPPLY IMPROVEMENT USING A POWER CONDITIONING SYSTEM WITH ENERGY STORAGE CAPABILITY
}

\author{
Domenico Casadei, Gabriele Grandi, Claudio Rossi \\ Department of Electrical Engineering - University of Bologna \\ Viale Risorgimento, 2 I-40136 Bologna
}

ITALY

\begin{abstract}
A Power Conditioning System (PCS) with energy storage capability is proposed as a viable solution for improving the quality and the reliability of the electric energy supply. Several tasks can be performed at the same time, such as reactive power compensation, current harmonic reduction, and smoothing of pulsating loads. Moreover, the PCS can operate as Uninterruptible Power Supply (UPS) during short time interruptions of the grid supply. In order to show the PCS performance, experimental tests have been carried out using a flywheel as storage device. The effectiveness of the PCS has been successfully verified in several operating conditions.
\end{abstract}

\section{KEY WORDS}

Uninterrupted Power Supply, Power Factor Compensation and Conditioning, Phase and Voltage Imbalances, Energy Storage System

\section{Introduction}

In practical applications a high reliability power supply is required for critical loads. In general, this requirement is fulfilled by a standard UPS configuration based on the series connection of a Voltage Source Inverter (VSI) between the grid and the load. The energy is usually stored in a lead acid battery bank. It can be noted that, about $90 \%$ of grid faults are very short (less of $1 \mathrm{~s}$ ), and in the remaining cases the UPS supplies the load for the time interval required for starting up a diesel or turbine generator set. In these cases the UPS supplies the load for no more than 30 seconds. As a consequence, for these high power and low energy applications the lead acid battery bank is often oversized, and an extra cost is paid for an energy reserve that will be never used.

Using new types of energy storage devices, such as superconducting magnets, supercapacitors or flywheel, which are more suitable for high power and low energy applications, it is possible to better exploit the energy reserve. These new storage devices allow additional tasks to be performed using the same hardware structure required for the UPS operation. The additional tasks consist of reactive power compensation, current harmonic reduction, load unbalance compensation, and smoothing of pulsating loads. In this way, the UPS behaves as a power conditioning system when the grid supply is present, improving significantly the power quality in the grid section next to the Point of Common Coupling (PCC).

The scheme of the proposed PCS is shown in Fig. 1. The energy Storage Device (SD) is connected to a static converter, which allows the bi-directional energy flow with the dc-link bus. The topology of this converter depends on the type of the energy storage device. The three-phase Voltage Source Inverter (VSI) is shunt connected to the PCC through three ac-link inductors. The PCC is supplied by the mains through a static switch that must be turned off during the operation of the power conditioning system as UPS. In this case, the PCS utilizes the stored energy to supply the load.

When the grid supply is present, the stored energy can be used to compensate flicker phenomena due to switching-on and -off of the load [4]. During these

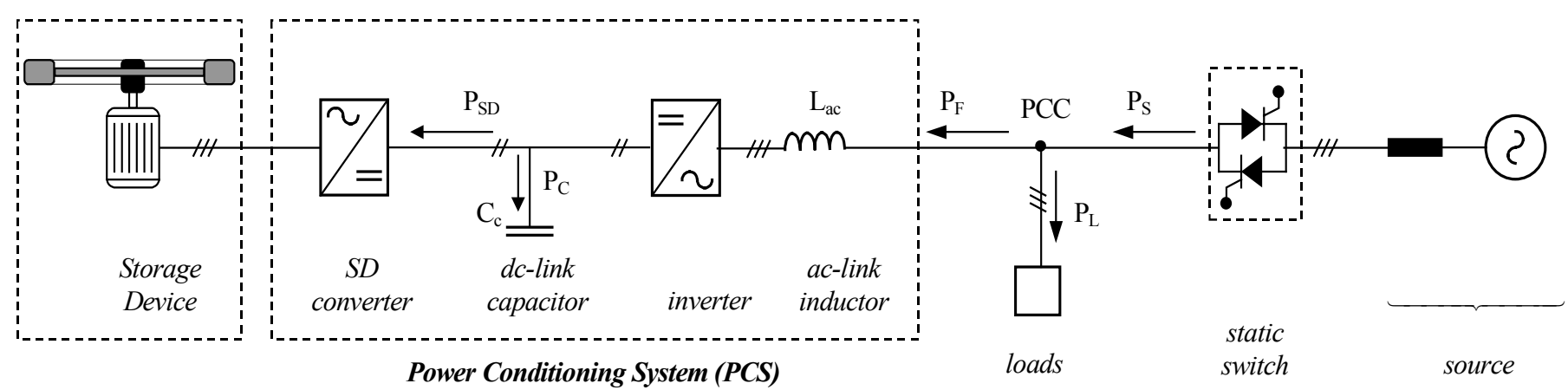

Fig. 1 Schematic drawing of the PCS structure 
transients the PCS exchanges a given quantity of the stored energy in order to deliver the difference between the instantaneous load power and its average value, which is supplied by the source.

Fig. 1 shows that the dc/ac section of the PCS connected to the mains has the same topology of a shunt active power filter [1]-[3]. Then, by means of a suitable control of the PCS it is also possible to compensate the load reactive power, to reduce the current harmonics of non linear loads, and to compensate unbalanced loads. These features are achieved by the direct control of the currents through the ac-link inductors in order to force the source currents to be balanced and sinusoidal for any operating condition. The source currents are synchronized with the fundamental positive sequence component of the source voltages. As a consequence, balanced and sinusoidal source currents with unity power factor can be obtained, even in presence of voltage perturbations coming from the mains [5], [6].

The flicker phenomena compensation and the active filter operation are achieved operating the PCS in "current source mode". When a perturbation of the mains is detected, the control system commutates the operating status from "current source mode" to "voltage source mode" and the PCS behaves as UPS. This commutation should be carried out without discontinuity in the voltage applied to the load.

A power conditioning system having all the described features has been realized in laboratory, according to the scheme represented in Fig. 1. The performance of the PCS has been verified by experimental tests and good results have been achieved both in active power filter operation and UPS operation.

\section{Analysis of the Energy Control System}

The implemented control system is constituted by two sections that allow the operation of the PCS respectively in current source mode when the grid supply is present and in voltage source mode when a grid fault occurs. A commutation strategy based on the monitoring of the source voltage vector $\overline{\mathrm{e}}_{\mathrm{S}}$ allows the commutation

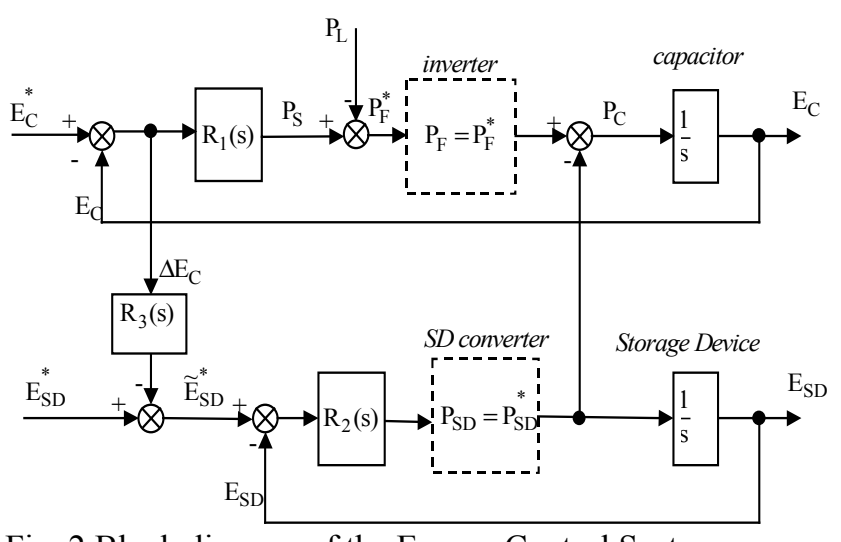

Fig. 2 Block diagram of the Energy Control System between the two control sections, without discontinuity in the voltage applied to the load.

\subsection{Current source mode}

During the operation of the PCS as current source the transfer of energy among the storage device, the dc-link capacitor and the ac network is performed by the Energy Control System (ECS). The analysis of the ECS can be usefully carried out in terms of power flow and energy balance [9], [10].

In order to explain the principle of operation of the ECS, reference is made to a load power perturbation. Any load power change determines a variation of the power supplied by the PCS and then a variation of the energy stored in the dc link capacitor. This energy should be quickly restored to its reference value using energy coming from the storage device. As a consequence, a power flow is established between the PCS and the point of common coupling. In this way at a switching-on of the load, the source is not required to supply instantaneously the full load power, but only an increasing percentage, being the remaining amount of power supplied by the PCS. During this transient the energy supplied by the PCS can be considered as coming directly from the SD unit. The use of the SD unit for smoothing load variations is necessary because the dc link capacitor has very low stored energy, and large dc-link voltage variations must be avoided in order to ensure a correct operation of the inverter.

The behavior of the ECS can be analyzed in terms of Laplace transform by the control scheme shown in fig. 2 . Here, the input control variables are the energy in the dclink capacitor $\mathrm{E}_{\mathrm{C}}^{*}$, and the energy in the storage device $\mathrm{E}_{\mathrm{SD}}^{*}$. The regulator $\mathrm{R}_{1}$ generates the reference source power $\mathrm{P}_{\mathrm{S}}$ on the basis of the dc-link capacitor energy error. The inverter power $\mathrm{P}_{\mathrm{F}}$ that should be exchanged from the mains to the inverter is obtained by subtracting the load power to the source power, $\mathrm{P}_{\mathrm{F}}=\mathrm{P}_{\mathrm{S}}-\mathrm{P}_{\mathrm{L}}$. The regulator $\mathrm{R}_{3}$ varies the reference value of the $S D$ energy on the basis of the error in the dc-link capacitor energy. $\mathrm{R}_{2}$ acts to keep the SD energy close to its reference value by exchanging power with the dc-link.

In order to analyze the compensation of flicker phenomena, it is useful to consider the block diagram shown in Fig. 3, which has been derived rearranging the block diagram of Fig. 2. By using the scheme of Fig.3 it is possible to determine the transfer function linking the source power to the load power.

Assuming for the regulators the following transfer functions

$$
\mathrm{R}_{1}(\mathrm{~s})=\mathrm{K}_{1}, \quad \mathrm{R}_{2}(\mathrm{~s})=\mathrm{K}_{2}, \quad \mathrm{R}_{3}(\mathrm{~s})=\mathrm{K}_{3},
$$

the source power is given by the following equation

$$
\mathrm{P}_{\mathrm{S}}(\mathrm{s})=\mathrm{G}_{\mathrm{C}}(\mathrm{s}) \mathrm{E}_{\mathrm{C}}^{*}+\mathrm{G}_{\mathrm{SD}}(\mathrm{s}) \mathrm{E}_{\mathrm{SD}}^{*}+\mathrm{G}_{\mathrm{L}}(\mathrm{s}) \mathrm{P}_{\mathrm{L}} \text {. }
$$

The expressions of $\mathrm{G}_{\mathrm{C}}(\mathrm{s}), \mathrm{G}_{\mathrm{SD}}(\mathrm{s}), \mathrm{G}_{\mathrm{L}}(\mathrm{s})$ are given in Appendix. Being the energy references $\mathrm{E}_{\mathrm{C}}^{*}$ and $\mathrm{E}_{\mathrm{SD}}^{*}$ 


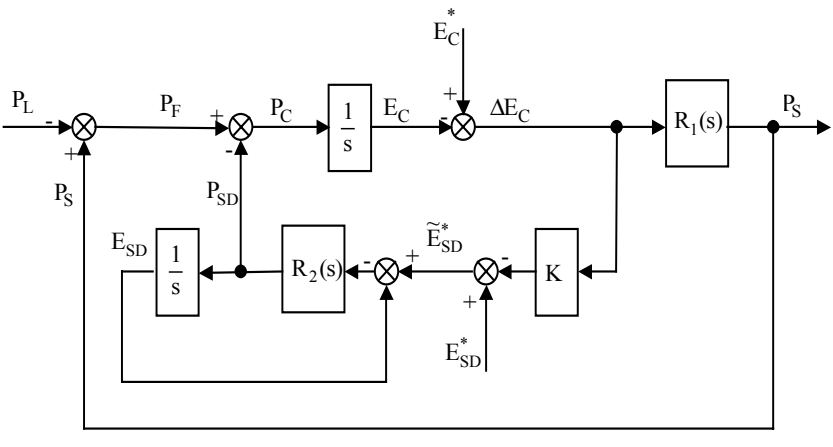

Fig. 3 Block diagram showing the relationship between $\mathrm{P}_{\mathrm{L}}$ and $\mathrm{P}_{\mathrm{S}}$

constant values, $\mathrm{G}_{\mathrm{C}}(\mathrm{s})$ and $\mathrm{G}_{\mathrm{SD}}(\mathrm{s})$ do not introduce steady state error in $\mathrm{P}_{\mathrm{S}}(\mathrm{s})$. As a consequence the open loop transfer function $\mathrm{F}(\mathrm{s})$ between the source power Ps and the load power $\mathrm{P}_{\mathrm{L}}$ can be expressed by

$F(s)=\frac{K_{1}\left(s+K_{2}\right)}{s\left(s+K_{3} K_{2}\right)}$.

It can be verified that this transfer function ensures a stable operation of the PCS for any load perturbation [11]

A smooth variation of the source power in response to a load power variation can be obtained by a proper tuning of the parameters $\mathrm{K}_{1}, \mathrm{~K}_{2}$ and $\mathrm{K}_{3}$.

The parameter $K_{2}$ of the regulator $R_{2}$ is related to the capability of the control system in following quick changes of $\widetilde{\mathrm{E}}_{\mathrm{SD}}^{*}$. The higher is $\mathrm{K}_{2}$, the faster is the SD energy regulator. The parameter $\mathrm{K}_{1}$ affects the behavior of the regulator $R_{1}$ in keeping constant the energy stored in the dc-link capacitor. The error in the capacitor energy determines the reference value of the source power, and through the parameter $\mathrm{K}_{3}$, determines also the variation of the $\mathrm{SD}$ energy level. In this terms, the parameter $\mathrm{K}_{3}$ defines the capability of the PCS to utilize the stored energy. With reference to a load switching-on transient, the energy level of the SD will be decreased by an amount related to the value of $K_{3}$. A high value of $K_{3}$ determines a deep discharge of the storage device, with a large amount of energy flowing from the PCS towards the PCC. This means a high smoothing effect on the source power variation, but requires storage devices with high rated energy. As a conclusion, the tuning of $\mathrm{K}_{3}$ defines the capability of the PCS in compensating flicker phenomena introduced by pulsating loads.

With reference to the possibility to compensate reactive power and current harmonics using the ECS described in this section, a detailed analysis has been presented in [3] and [6]. Here only some comments will be given. The energy variation on the dc-link capacitor determined either by compensation of load unbalance or by operation with unbalanced source voltage are very small compared to those of pulsating loads, and they do not produce appreciable changes on the reference value of the SD energy. Then, with reference to the ECS of Fig. 2 it can be assumed that the upper control loop is always active, whereas the lower control loop operation is involved only during large variation of the load power.

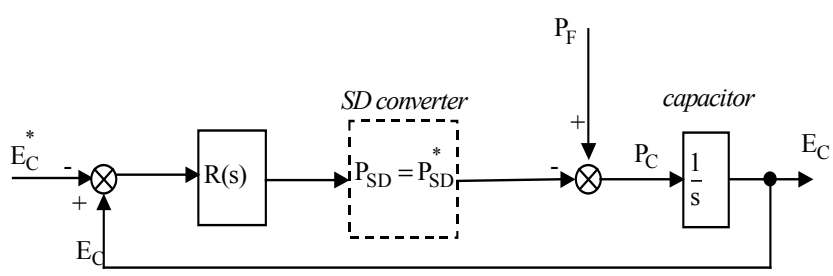

Fig. 4 Block diagram of the Energy Control System used in the voltage source mode

\subsection{Voltage source mode}

During grid faults, the operation of the PCS as voltage source is obtained by a simple control system which allows the supplying of the load using the energy stored in the SD. The SD converter discharges the storage device determining a power flow from the SD to the dc-link in order to keep its voltage close to the reference value. The block diagram of the ECS employed in the voltage source mode is shown in Fig. 4. The inverter is controlled by a Space Vector Modulation (SVM) technique that supplies the load with three-phase balanced system of sinusoidal voltages, corresponding to the grid rated voltage.

\section{Implementation of the Control System}

The energy control system required for operating the PCS in the current source mode has been implemented introducing some changes with respect to the basic scheme of Fig. 2.

The energy level in the dc-link capacitor is kept under control using the capacitor voltage $\mathrm{V}_{\mathrm{C}}$ as control variable. The source power is regulated using the source current $\overline{\mathrm{i}}_{\mathrm{S}}$ as control variable [6]. Figs. 5 and 6 show the control system modified according to these considerations.

The reference source current $\overline{\mathrm{i}}_{\mathrm{S}}^{*}$ is obtained by multiplying the unity vector $\hat{\mathrm{v}}_{\mathrm{S}}^{+1}$, by the reference source current magnitude $\mathrm{I}_{\mathrm{S}}^{*}$, where:

- the unity vector $\hat{\mathrm{v}}_{\mathrm{S}}^{+1}$ is in phase with the positive sequence fundamental component of the line to neutral voltage $\hat{v}_{S}$, and it is generated by a Three Phase Locked Loop algorithm [7]. This algorithm operates correctly even in the case of unbalanced and non sinusoidal voltages [8].

- the reference source current magnitude $\mathrm{I}_{\mathrm{S}}^{*}$ is generated by the regulator $\mathrm{R}_{1}(\mathrm{~s})$, which operates on the instantaneous error between the reference value $\mathrm{V}_{\mathrm{C}}^{*}$ and the actual value $\mathrm{V}_{\mathrm{C}}$ of the dc-link voltage. 


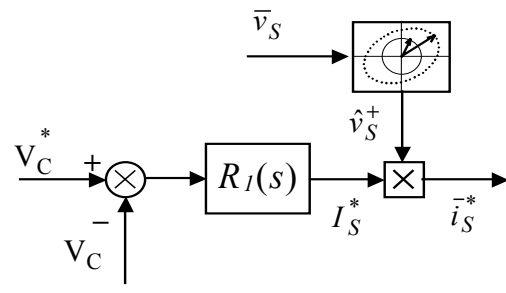

Fig. 5 dc-link voltage controller

The ac current regulator then synthesizes the reference source current. This regulator operates in order to keep the source current $\bar{i}_{S}$ close to its reference value $\bar{i}_{S}^{*}$ [3].

The regulator $\mathrm{R}_{2}(\mathrm{~s})$ of the energy control system keeps under control the energy level in the storage device. In the implemented control system this has been achieved controlling the voltage across the supercapacitors, or the rotating speed of the flywheel. This control is performed using the converter between the dc-link and the storage device. The topology of the converter is a dc/dc chopper in the case of supercapacitors, and a three-phase VSI in the case of flywheel driven by an induction machine.

The commutation strategy between current source mode and voltage source mode is implemented in a supervisor algorithm. When the grid is present, the supervisor algorithm calculates the instantaneous value of the source voltage vector $\bar{v}_{S}$ by monitoring the source voltages. Assuming balanced and sinusoidal supply voltages, the voltage vector $\overline{\mathrm{v}}_{\mathrm{S}}$ rotates at constant speed describing a circular locus. In case of unbalanced or non sinusoidal supply voltages, the trajectory described by the voltage vector $\overline{\mathrm{v}}_{\mathrm{S}}$ changes from circular causing variations of the magnitude and angular velocity. Perturbation of the supply voltages, such as voltage sags, large voltage drops, zero voltage conditions, cause large deviations of the voltage vector trajectory. A critical circular region has been defined in order to detect these perturbations and to start the commutation sequence. If the voltage vector lays in the critical region for a time interval greater than a given value, the supervisor algorithm disables the current source mode, drives the opening of the static switch, and when the source currents are almost zero, enables the operation of the PCS in voltage source mode. During the commutation sequence, the phase angle of the source voltage is estimated allowing the PCS to supply the load without appreciable

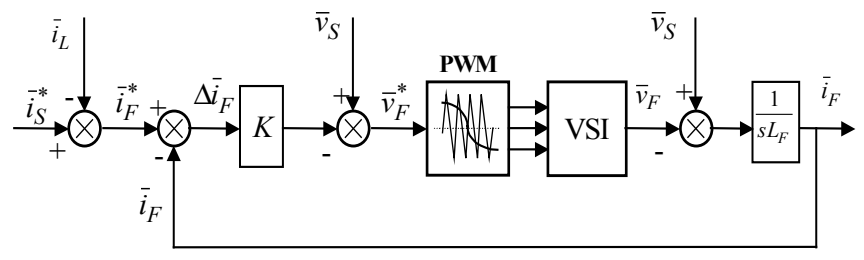

Fig. 6 ac current controller

voltage discontinuity. During the operation of the PCS in voltage source mode, the grid voltage is continuously monitored and when the source voltage vector leaves the critical region permanently, the control system commutates from the voltage source mode to the current source mode. During this commutation a PLL algorithm allows to synchronize the voltage vector applied to the load with the restored source voltage. In this way, the commutation is carried out without discontinuities on the voltage applied to the load.

\section{Experimental results}

A PCS having the characteristics shown in Tab. I has been realized in laboratory. A flywheel driven by an induction machine has been used as energy storage device. The system configuration is the same as in Fig. 1, therefore the PCS is able to compensate flicker phenomena, to behave as active power filter, and to ensure the continuity of the load supply during short time interruption of the grid.

The control system has been implemented on a PPC $333 \mathrm{MHz}$ DSP based board, including A/D converters and an encoder interface. The board includes also a second DSP (TMS320F240) to generate the PWM signals for both the converters. As a first step, the capability of the PCS to operate as active filter has been verified. Fig. 7 shows the compensation of the reactive power of a R-L linear load. Fig. 8 shows the compensation of the current harmonics of a non linear load represented by a three phase diode rectifier.

A single-phase load has been connected to the PCC to represent an unbalanced load. The results obtained, showing the effectiveness of the compensation are illustrated in Fig.9.

Pulsating loads have been considered to verify the capability of the PCS to compensate flicker phenomena.

Table I - Main data of the PCS prototype

\begin{tabular}{|l|c|ll|}
\hline utility voltage & $\mathrm{V}_{\mathrm{S}}$ & 220 & {$[\mathrm{~V}]$} \\
\hline utility frequency & $\mathrm{f}_{\mathrm{S}}$ & 50 & {$[\mathrm{~Hz}]$} \\
\hline 3 phase ac-link inductor & $\mathrm{L}_{\mathrm{ac}}$ & 2 & {$[\mathrm{mH}]$} \\
\hline static switch & \multicolumn{3}{|l|}{ TRIACS -3 phase } \\
\hline
\end{tabular}

\begin{tabular}{|l|c|lr|}
\hline dc-link capacitance & $\mathrm{C}_{\mathrm{C}}$ & 10 & {$[\mathrm{mF}]$} \\
\hline flywheel inertia & $\mathrm{J}_{\mathrm{SD}}$ & 0.3 & {$\left[\mathrm{~kg} \cdot \mathrm{m}^{2}\right]$} \\
\hline reference value of dc-link voltage & $\mathrm{V}_{\mathrm{C}}^{*}$ & 450 & {$[\mathrm{~V}]$} \\
\hline reference value of flywheel speed & $\mathrm{n}_{\mathrm{SD}}^{*}$ & 3000 & {$[\mathrm{rpm}]$} \\
\hline
\end{tabular}


Fig. 10 shows the behaviour of the PCS during the transient caused by a load switching-on. The effects of the PCS is to smooth the corresponding step of the source power by supplying the load at the beginning of the transient. Fig. 11 shows the transient response caused by a load pulsating at a frequency of $1 \mathrm{~Hz}$, with a duty cycle of $10 \%$. The effect of the PCS is to keep the source current amplitude almost constant and equals to the mean value of the load current. This is achieved exchanging a fraction of the energy stored in the flywheel.

Figs. 12-14 show the behaviour of the system during a short interruption of the source supply. It can be noted that the system is able to supply the load during the grid fault by employing the mechanical energy stored in the flywheel (Fig. 12). The details of the commutation between the two operating mode, i.e. current source and voltage source, are represented in Fig. 13 and 14. Both the commutations are carried out without significant discontinuities in the load current that means continuity of service of the critical loads.

\section{Conclusion}

The performance a PCS with the capability to meet several power quality requirements has been analysed and verified by experimental tests. An analytical approach has been used to determine the parameters of the three regulators. A PCS prototype with a rated power of 30 kVA has been realized in laboratory. Several tests have been carried out in different operating conditions. It has been verified that this system is able to compensate reactive power and current harmonics due to non-linear loads. Furthermore, the results obtained have shown that the presence of an energy storage device makes it possible to reduce the source current variations due to pulsating loads, and to ensure the continuity of the supply during short time utility faults.

The experimental results are quite satisfactory, showing the effectiveness of the proposed PCS in improving the power quality and the reliability of the power supply

\section{References}

[1] H.Fujita, H.Akagi, The Unified Power Quality Conditioner: The Integration of Series Active Filter and Shunt Active Filters, Proc. IEEE-PESC Conf., Baveno, ITALY, 1996, 494-501.

[2] L.A. Moran, J.W. Dixon, R.R. Wallace, A threephase active power filter operating with fixed switching frequency for reactive power and current harmonic compensation, IEEE Trans. on IE, Vol. 42, No.4, 1996, 402-408.

[3] D. Casadei, G. Grandi, U. Reggiani, C. Rossi, Control methods for active power filters with minimum measurement requirements, Proc. IEEE-
APEC Conf., Dallas-TX USA, 1999, Vol. 2, 11531158.

[4] D. Casadei, G. Grandi, U. Reggiani, G. Serra, Analysis of a Power Conditioning System for Superconducting Magnetic Energy Storage, Proc. IEEE-ISIE Conf., Pretoria South Africa, 1998, 546551.

[5] D. Casadei, G. Grandi, U. Reggiani, G. Serra, A. Tani, Behavior of a Power Conditioner for $\mu$-SMES Systems under Unbalanced Supply Voltages and Unbalanced Loads, Proc. IEEE ISIE Conf., Bled Slovenia, 1999, Vol.2 539-544.

[6] D. Casadei, G. Grandi, C. Rossi, Effects of Supply Voltage non-Idealities on the Behavior of an Active Power Conditioner for Cogeneration Systems, Proc. IEEE-PESC Conf., Galway, Irland, 2000, Vol.3 1312-1317.

[7] F. M. Gardner, Phaselock Techniques. (New York: Wiley, 1979).

[8] S. K. Chung, A Phase Tracking System for Three Phase Utility Interface Inverters, IEEE Transaction on Power Electronics, Vol. 15 no. 3, May 2000, 431438

[9] D. Casadei, G. Grandi, U. Reggiani, C. Rossi, Active AC Line Conditioner for a Cogeneration System, Proc. European Confer. on Power Electronics and Applications EPE99, Lausanne, Switzerland, 1999.

[10] F. Negrini, U. Reggiani, C. Rossi, G. Grandi, D. Casadei, et. al, Recent Developments on microSMES System Project at the University of Bologna, Proc. of EESAT, Orlando-FL, USA, 2000.

[11] G.Grandi, D.Casadei, C.Rossi, A Parallel Power Conditioning System with Energy Storage Capability for Power Quality Improvement in Industrial Plants, Proc. European Confer. on Power Electronics and Applications EPE'01, Graz, Austria, 2001

\section{Appendix}

With reference to the control scheme of Fig. 3, the expression of $\mathrm{G}_{\mathrm{C}}(\mathrm{s}), \mathrm{G}_{\mathrm{SD}}(\mathrm{s}), \mathrm{G}_{\mathrm{L}}(\mathrm{s})$ are

$$
\begin{aligned}
& \mathrm{G}_{\mathrm{C}}(\mathrm{s})=\frac{\mathrm{K}_{1} \mathrm{~s}^{3}+\mathrm{K}_{1} \mathrm{~K}_{2} \mathrm{~s}^{2}+\mathrm{K}_{1} \mathrm{~K}_{2} \mathrm{~s}}{\mathrm{~s}^{3}+\left(\mathrm{K}_{1}+\mathrm{K}_{2}+\mathrm{K}_{3} \mathrm{~K}_{2}\right) \mathrm{s}^{2}+\mathrm{K}_{1} \mathrm{~K}_{2} \mathrm{~s}+\mathrm{K}_{1} \mathrm{~K}_{2}} \\
& \mathrm{G}_{\mathrm{SD}}(\mathrm{s})=\frac{\mathrm{K}_{1} \mathrm{~K}_{2} \mathrm{~s}^{2}+\mathrm{K}_{2} \mathrm{~s}}{\mathrm{~s}^{3}+\left(\mathrm{K}_{1}+\mathrm{K}_{2}+\mathrm{K}_{3} \mathrm{~K}_{2}\right) \mathrm{s}^{2}+\mathrm{K}_{1} \mathrm{~K}_{2} \mathrm{~s}+\mathrm{K}_{2}} \\
& \mathrm{G}_{\mathrm{L}}(\mathrm{s})=\frac{\mathrm{K}_{1} \mathrm{~s}^{2}+\mathrm{K}_{1} \mathrm{~K}_{2} \mathrm{~s}+\mathrm{K}_{2}}{\mathrm{~s}^{3}+\left(\mathrm{K}_{1}+\mathrm{K}_{3} \mathrm{~K}_{2}\right) \mathrm{s}^{2}+\mathrm{K}_{1} \mathrm{~K}_{2} \mathrm{~s}+\mathrm{K}_{2}} .
\end{aligned}
$$




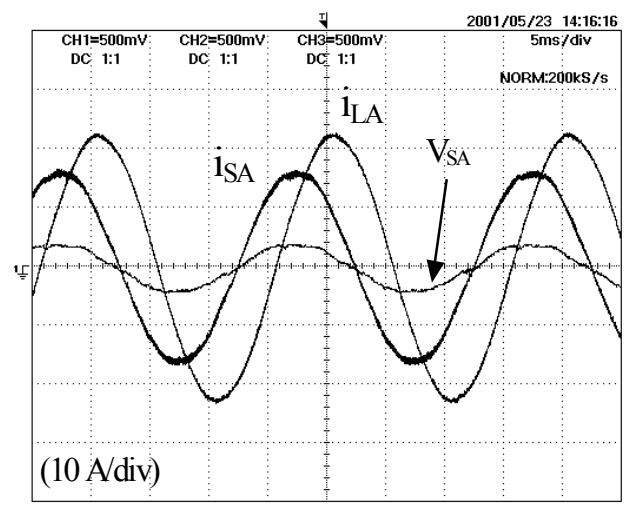

Fig. 7 Compensation of load reactive power

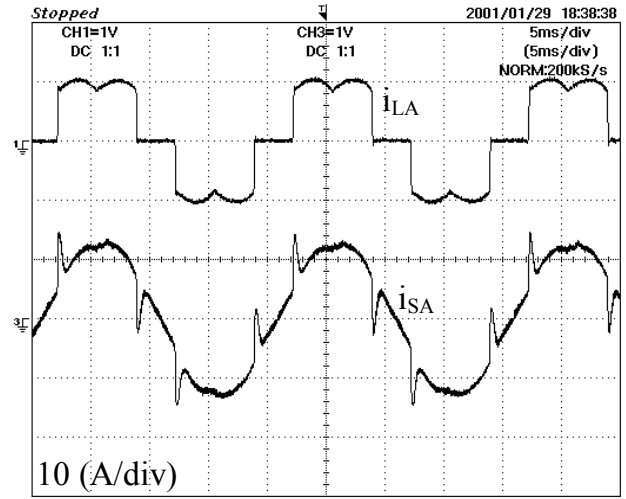

Fig. 8 Compensation of current harmonics

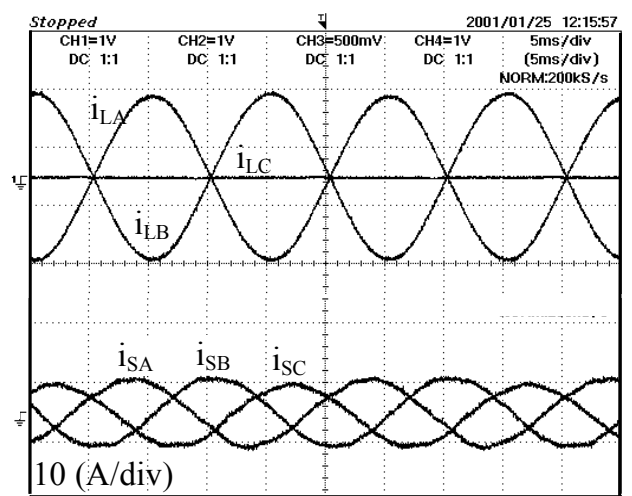

Fig. 9 Compensation of load unbalance

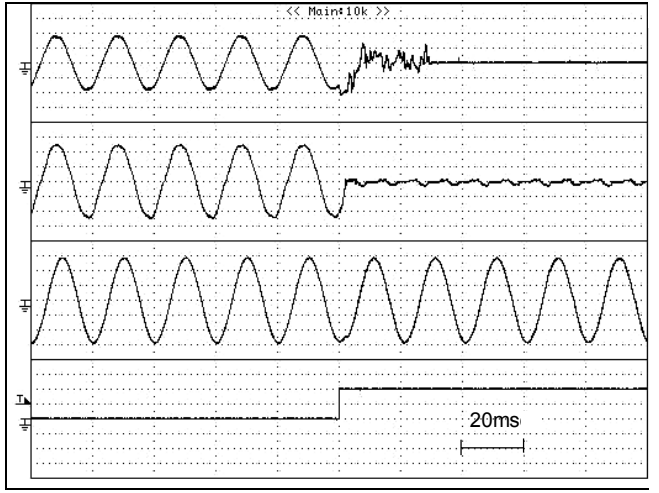

Fig. 13 UPS operation: detailed view of the commutation: from current source mode to voltage source mode

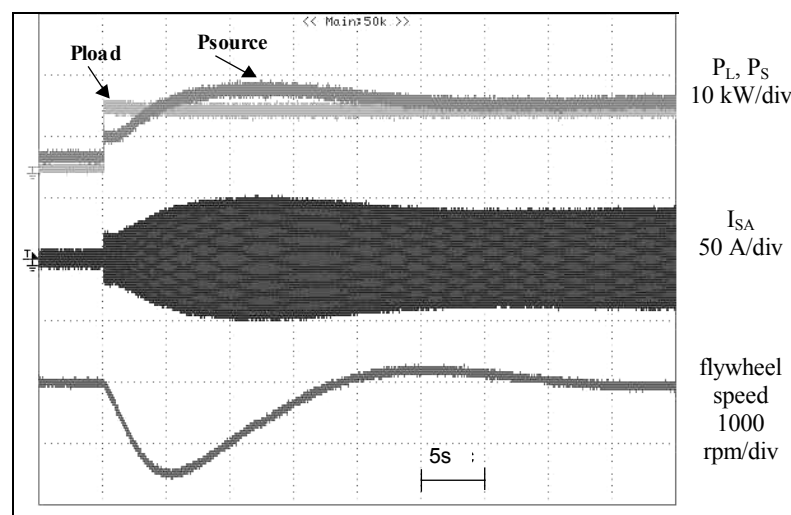

Fig. 10 Response of the PCS to a load switching-on

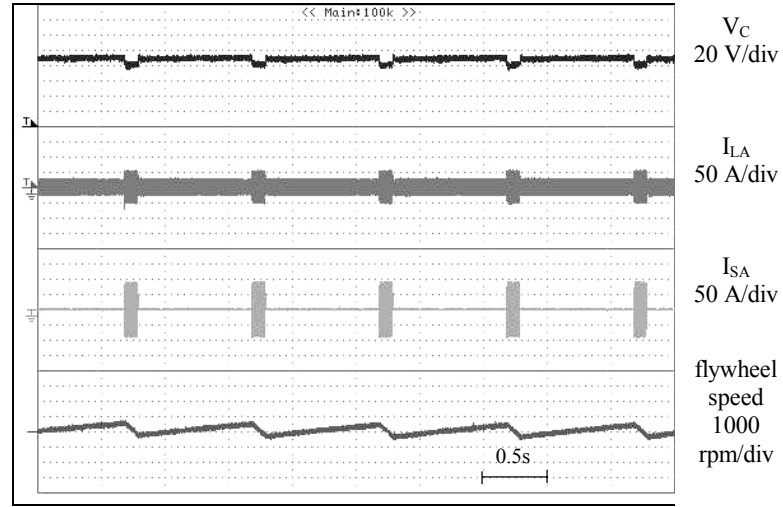

Fig. 11 Response of the PCS to a pulsating load

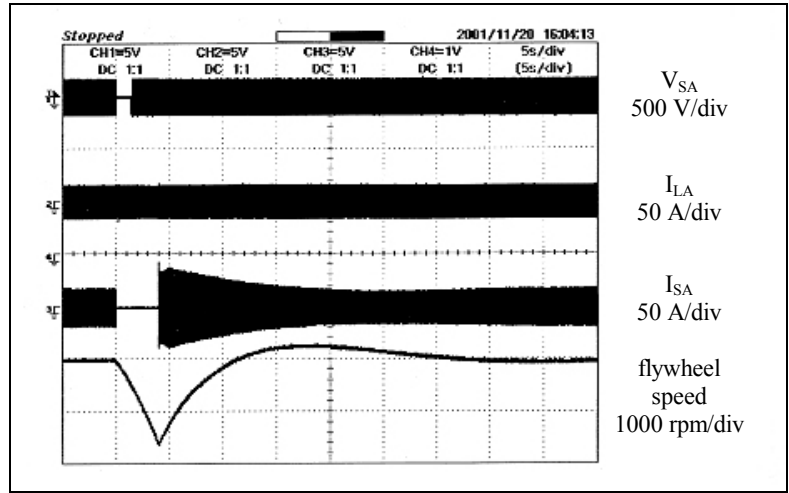

Fig. 12 Operation of the PCS during a $1.5 \mathrm{~s}$ grid faults

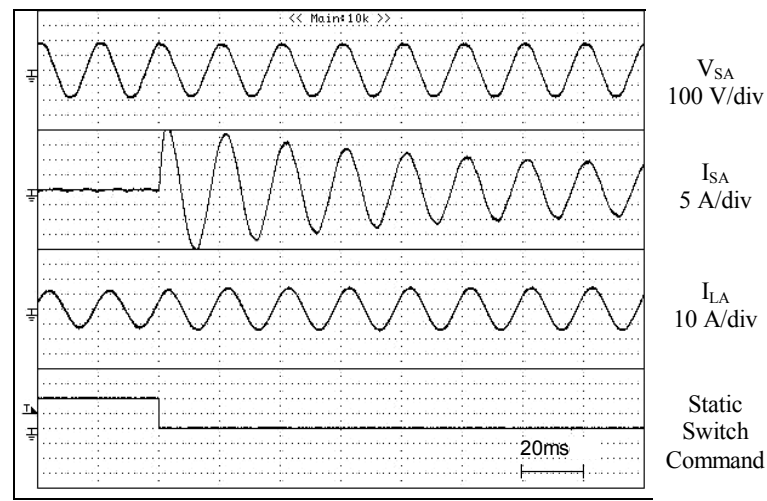

Fig. 14 UPS operation: detailed view of the commutation: from voltage source mode to current source mode 